\title{
Who indicates Caesarean section in Romania? A cross-sectional survey in tertiary level maternity on childbirth patients and doctors' profiles
}

\section{Anca Angela Simionescu ( $\square$ asimion2002@yahoo.com )}

Carol Davila University of Medicine and Pharmacy Filantropia Hospital https://orcid.org/0000-00029334-0199

\section{Alexandra Horobet}

Academia de Studii Economice din Bucuresti

\section{Erika Marin}

Academia de Studii Economice din Bucuresti

\section{Lucian Belascu}

Universitatea Lucian Blaga din Sibiu

Research article

Keywords: cesarean section, vaginal birth, health policies, pain, labor, Romania

Posted Date: October 23rd, 2020

DOI: https://doi.org/10.21203/rs.3.rs-39240/v3

License: (c) (i) This work is licensed under a Creative Commons Attribution 4.0 International License. Read Full License 


\section{Abstract}

Background. Cesarean section (C-section) rate in Romania is the second-highest in the European Union (44.1\% in 2017), and the number of C-sections performed in the country has increased in the past decades. Given how common C-section is now, it is important to gain insight into the practice and perceptions of patients and doctors in countries with high C-section rates. The objectives are 1) to compare the preferred modes of birth among women; 2 ) to draw a profile of patients and doctors in whose case the actual birth method is different from the preferred method; and 3) to analyze the way Romanian women want to give birth.

Methods. We conduct a statistical analysis based on an observational, analytical, and cross-sectional survey on 117 singleton pregnant women more than 36 weeks in spontaneous labor in tertiary level maternity in Romania. Various statistical tests have been used to indicate statistical significance.

Results. We calculate an increase of almost $58 \%$ in actual childbirth mode against preferred childbirth by C-sections, rather difficult to justify based only on medical emergencies. There are 22 patients with nonconcordant C-section indications between preferred and actual mode of birth, 7 of them (31.8\%) preferred natural birth and 15 (68.2\%) preferred C-section. The profiles of patients with concordant and nonconcordant delivery modes are different and indicate a statistically significant difference between the preference for delivery and actual birth method. Patients who preferred vaginal birth, but gave birth by Csection, are mature and more educated women, in the middle to high-income category, mostly attended by consultant doctors and specialists. Doctors' profiles show that specialists and consultants attend the largest share of non-concordant births, while residents and young senior doctors attend mostly vaginal births.

Conclusions. We emphasize health system particularities in Romania as triggers of high C-section rates that favor women's preferences against C-section medical indication. Improving patients' confidence in the health care system, built on competence and fitted hierarchical team position may lead to choosing the optimal way of birth for childbirth safety and pain control.

\section{Introduction}

Evidence from database registries shows a considerable increase in birth rates by cesarean section (Csection) especially in urban areas of middle and high-income countries, reaching a rate of up to $50 \%$ of deliveries in several countries [1-3]. Former European communist states have higher C-section rates when compared with Western European countries; in 2018, Romania had a $44.50 \%$ rate, Bulgaria $-44.58 \%$, Poland $-38.92 \%$, and Hungary - $38.03 \%$ [4]. Data between 2009 and 2017 reveal a decline of $65 \%$ of infant death, but with an increased by $44.11 \%$ of C-sections in Romania $[5,6]$.

Although WHO does not any longer recommend an ideal rate for C-sections, the range of $10-15 \%$ at the population level is used pragmatically for international monitoring aiming at ensuring maternal and 
perinatal health benefits and reduce potential harms [2,7]. Given how common C-section is now, it could be of much importance to understand this phenomenon in countries with high C-section rates.

Betrán et al. identify two categories of interventions to reduce unnecessary C-sections: clinical (obstetrical) interventions and non-clinical interventions that could overlap each other [7]. Non-clinical interventions target the psychosocial level of women and childbirth education, but also guidelines for healthcare professionals and second-opinion on C-sections[8].

\section{Objectives}

The objectives of this study are 1) to analyze the way Romanian women want to give birth, and 2) to draw a profile of patients and doctors in whose case the actual birth method is different from the preferred method after admission in the labor ward. Both objectives are important for understanding the patients' preference for birth delivery methods, and for capturing patients and doctors' characteristics that are connected to these methods. Moreover, this helps a better apprehension of the motives behind changes in patients' preference regarding the way of giving births and of the high rate of C-sections in Romania, but also in similar countries.

\section{Materials And Methods}

We conducted an observational, analytical, and cross-sectional non-anonymous survey based on hospital database registries and on a questionnaire distributed at a tertiary level maternity hospital in Bucharest, Romania, in February 2014, within a research project (Additional file: Distributed questionnaire]. The questionnaire was discussed with doctors from the maternity and further validated. The final number of respondents, 117 , offers a level of confidence of $95 \%$ and an error margin of $9 \%$ when benchmarked against all births in Romania in 2014, and is due to available data from the project.

The questionnaire was distributed to all full-term pregnant women when admitted in the hospital for giving birth, and when discharged at home from hospital during February 2014. Inclusion criteria were more than 36-weeks gestational age, singleton pregnancy, expecting a child without assessed congenital anomalies, and understanding written Romanian. Participation was voluntary, and the study was approved by the Hospital's Commission of Ethics.

A 1-10 scale was used to assess birth experience and pain during labor, and doctors' (obstetrician and anesthetist) and midwives' performance (1-worst; 10 - best). Patients' assessments were transformed into the following categories: Very good -9 to 10 ; Good - 7 to 8; Satisfactory - 5 to 6; Not Satisfactory 1 to 4 . 
We conduct a statistical analysis using the Statistica software. Firstly, we performed descriptive statistics of the responses in the form of frequencies (absolute and relative), and means and standard deviations, depending on the type of variables (qualitative versus quantitative). We compared preferred and actual modes of delivery using the Chi-square and V-square tests, and we applied the t-test for independent samples differences in mean scores. We also used Mc-Nemar Non-parametric significance tests for two dependent samples for the analysis of the matched samples presenting the choice of pregnant women before delivery and the actual method of birth (the after effect). P-values of less than $0.05(p<0.05)$ indicate statistical significance.

\section{Results}

There were 168 deliveries in the hospital in February 2014, of which 51 spontaneously, 10 instrumental vaginal delivery (forceps in 8 cases and vacuum in 2 cases), and 107 through $\mathrm{C}$-section. The final number of women who consented to participate in our survey was 117 (69.64\%). Their demographic characteristics are presented in Table 1. 63.3\% of respondents were between 26 and 35 years of age (worked in the private sector, as employees or business owners (69.3\%), and were higher education graduates (67.5\%). $64.1 \%$ of them were in the middle-income category, married (81.2\%), and lived in urban areas $(79.5 \%)$.

\section{Table 1. Demographic characteristics of survey respondents}

On the day of labor ward admission, according to the birth plan established in the third trimester with the doctor, $70.1 \%(n=82)$ of women preferred vaginal birth, $28.2 \%(n=33)$ preferred C-section and two women $(1.7 \%)$ did not respond. Younger and more educated women, mostly living in urban areas and the low to middle-income categories, showed a higher preference for a vaginal birth (Table 2).

\section{Table 2. Respondents' characteristics depending on the mode of delivery choice}

Out of the 117 respondents, 55.6\% ( $n=65)$ had vaginal births and $44.4 \%(n=52)$ had C-sections (Table 3 and Figure 1). For 19 patients, the preferred and actual ways of delivery were different. None of the women who chose $\mathrm{C}$-section had undergone vaginal birth.

\section{Table 3. Preferred versus actual mode of delivery of women}

\section{Figure 1. Sample structure based on preferred versus actual mode of delivery}

The non-parametric significance tests show that the initial preferences of women for vaginal birth versus C-section were significantly different, and the highest preference was for vaginal birth - Chi-square test value $=60.61, p<0.05)$. The $V$-square test, which corrects for sample size and uncertainty, confirms the results of the Chi-square test (value $=59.64, \mathrm{p}<0.05$ ). The McNemar Chi-square test shows a significant difference (value=9.81, $p<0.05$ ) between the preference for a delivery method and the actual birth method. 
Concerning patients' stated indication for C-section, the profile of the 41 respondents is the following: $83.7 \%$ were aged below 35 years, lived in urban areas, had lower to middle income, and were more educated (76.7\% were graduates of tertiary education). Out of them, $16(39 \%)$ preferred natural birth, and 25 (60.9\%) preferred C-section. Of the 16 women that preferred natural birth and stated an indication for C-section, 3 (18.7\%) gave birth by vaginal way, and 13 (81.3\%) gave birth by C-section. All women that preferred $\mathrm{C}$-section and declared an indication for $\mathrm{C}$-section gave birth this way.

C-section on request was preferred by $6.8 \%(n=8)$ of women. They were aged below 35 years, were higher education graduates, 6 out 8 had middle to high income and lived in urban areas. Five out of 8 were married, two were in a partnership, and all were giving birth to their first child. Seven out of these 8 women stated no indication for C-section, and 1 declared an indication. For all 8 women, C-section indications were not concordant when patients' and doctors' indications in medical records were compared.

Scarred uterus is the most frequent indication for C-section (30.76\% of C-sections) and all breech presentations were delivered by $\mathrm{C}$-section, although some patients would have preferred a natural birth. Besides these indications, there were 22 primiparas with non-concordant C-section indications between preferred and actual mode of birth; 7 of them (31.8\%) preferred natural birth and 15 (68. 2\%) preferred Csection. The most frequent non-concordant C-section indications were placenta praevia, oligohydramnios $<39$ weeks, and failed induction of labor.

Almost half of women that preferred vaginal birth $(49=59.8 \%)$ and $48.5 \%$ of women that preferred Csection chose epidural anesthesia. Most women that preferred vaginal birth also preferred epidural anesthesia $-59.5 \%(n=49) ; 38$ of them $(77.6 \%)$ had vaginal birth, while $11(22.4 \%)$ had C-section. Eighteen out of 33 women $(54.5 \%)$ that preferred C-section were primipara, and all of them gave birth by C-section.

Time spent in the labor ward, birth pain perception and professional doctors' degree are presented from women's perspective of preferred versus actual type of birth (Table 4). Patients with concordant vaginal births are younger, in the middle to low-income category, less educated, but have undergone all recommended screening during their pregnancies. They were attended mostly by consultants and preferred epidural anesthesia. They assessed birth experience as Good to Very good and birth pain as good. Patients with concordant C-section are in an elder group, with middle income mostly, and educated. They were attended mostly by consultants and specialists, and have the lowest preference for epidural anesthesia. They assess highly their birth but rate birth pain as Satisfactory only. The patients with nonconcordant modes of delivery are mature women (mostly aged between 26 and 35 years old), in the middle to high-income category, and more educated. They mostly preferred epidural anesthesia, assessed their birth as Good to Very good, and their birth pain as Goo

\section{Table 4. Patients' profiles depending on preferred versus actual mode of delivery}

Table 5 presents professional degree of doctors' profiles depending on patient and birth characteristics. Resident and young senior doctors attended younger patients, in the middle to low-income category, 
which have undergone full sets of laboratory tests during pregnancy. They delivered mostly vaginal and concordant births, and received Good to Very good assessment for deliveries and birth pain. Specialists and consultant doctors attended more mature women, in the middle to high-income category, mostly with higher education and full prenatal test screenings. They attended the largest share of non-concordant births. Their patients assess in a somewhat similar manner birth experiences and birth pain.

\section{Table 5. Professional degree of doctors' profiles depending on patient and birth characteristics.}

Fifty-two women (44.4\%) gave birth during working hours (DW - 8 a.m. -3 p.m.); 39 births (33.3\%) occurred during the evening shift (AOD - 3 to 10 p.m.) and 26 births (22.2\%) during the night shift (AON 10 p.m. to 8 a.m.). There were more C-sections than vaginal births performed DW, but more vaginal births than C-sections were performed after working hours. Concordant births took place mostly AOD for vaginal births (25), but DW for C-sections (23) - Figure 2.

\section{Figure 2. Preferred versus actual modes of delivery and birth times}

Patients distinguish clearly between birth pain alone and their overall birth experience; they rate pain on the lower part of the scale, although birth experience is evaluated on a higher note. Patients' mean scores for their birth pain are $7.535(S D=2.756)$ for vaginal birth and 6.111 ( $S D=3.745)$ for $C$-section; thus, patients that would have chosen $\mathrm{C}$-section assessed lower their birth pain $(p<0.05)$. The mean scores based on the actual mode of delivery are $7.625(S D=2.666)$ for vaginal birth and $6.511(S D=3.501)$ for $C$ section ( $p>0.05)$.

Birth pain is best rated for AOD (7.73), followed by AON (7.33) and DW (6.59). The largest proportion of unsatisfied women by their birth pain is found for patients that gave birth DW. The average scores of patients' assessment of their birth and birth pain depending on the time of birth indicate that women rate the highest births AON (9.04) compared to births during daytime ( 8.83 is the score for DW and AOD).

Patients that preferred C-section offer higher mean scores for the medical personnel, compared to patients that preferred vaginal birth $(p>0.05)$ - $9.97(S D=0.40)$ against $9.91(S D=0.18)$ for obstetricians, $9.69(S D=0.99)$ against $9.69(S D=0.68)$ for anaesthetists, and $9.75(S D=0.67)$ versus $9.72(S D=0.80)$ for midwives. Similarly, patients that gave birth by $\mathrm{C}$-section scored higher the medical personnel than patients that had a vaginal birth $(p>0.05)-9.98(S D=0.45)$ against $9.88(0.14)$ for obstetricians, 9.76 $(S D=0.84)$ against $9.59(S D=0.74)$ for anaesthetists, and $9.76(S D=0.68)$ versus $9.71(S D=0.82)$ for midwives. Overall, though, concordance is not a discriminatory factor for personal medical assessment.

\section{Discussion}

In our study, $28.2 \%$ of women preferred C-section, and $70.1 \%$ preferred vaginal birth. After birth, the percentage of C-sections increased to $44.4 \%$, showing a difference between actual versus preferred mode of delivery of 16.2 percentage points $(57.4 \%)$ in favour of C-section. The preference for C-section in our sample seems higher than 0.3 to $16 \%$ shown by meta-analyses and other observational reviews[9-11]. 
Doctors' profiles show that specialists and consultants attended the largest share of non-concordant births, while residents and young senior doctors attended mostly vaginal births. There are no significant differences in the time spent in the labor room among doctors' categories, except residents that had the highest share of births beyond 5 hours (58.3\%). But patients do not seem to differentiate their assessment of birth and birth pain depending on the type of doctor that attended their delivery. We found a negative correlation between the time spent in the labor room and birth pain assessment. Less than 5 hours spent in the labor room are correlated with Very good scores for birth and birth pain.

Studies from countries with a low incidence of C-section show that patient's satisfaction is not influenced by the delivery method, but patients would have preferred to be involved in the decision of delivery method [12,13]. In our study, patients' mean scores for their birth experience depending on their preferred mode of delivery is $8.74(S D=1.84)$ for vaginal birth and $9.21(S D=1.63)$, which means that patients that would have chosen $\mathrm{C}$-section assess better their birth. At the same time, the mean scores based on the actual mode of delivery are $8.68(S D=1.71)$ for vaginal birth and $9.13(S D=1.84)$ for $C$-section birth.

The average total monthly income of Romanian households increased by $80.3 \%$ between 2006 and 2014, and it almost further doubled in 2019, signalling higher population access to more sophisticated healthcare procedures. This is coupled with an increase in the average age of mothers at first birth from 22.3 years in 1990 to 27.4 years in 2018 [14]. Moreover, the private sector offers alternatives for the entire range of medical services and units. In 2014, $30.6 \%$ of Romanian hospitals were under private ownership, compared to 1990, when all 423 hospitals were public. The increase in hospital beds in the private sector was 97.2 times between 1999 and 2014 [15]. Correspondingly, women giving birth are not reluctant in paying for the C-section bill either in a public or private hospital, although the costs are not meager. Therefore, it is not surprising to find that the percentage of women giving birth in some Romanian clinics and hospitals reached $80 \%[15]$.

To the best of our knowledge, this is the first survey about the preferred versus actual mode of birth in a Romanian hospital. There seems to be a degree of awareness and mature consciousness and preparedness towards the excess of C-section in Romania, as proven by some recent political actions. In 2019, the Commissions for Public Health and Human Rights, Equal Opportunities, Cults, and Minorities of the Romanian Parliament organized a debate on public strategies and policies for supporting natural birth and management of Cesareans in Romania [16]. The debate ended with a statement that encourages giving birth by vaginal delivery, which adds to the consolidation of indications for C-section at the level of the Romanian Gynecological Society. Other countries' example $[17,18]$ - proves that interventions focused only on the medical side were not successful.

Strengths and limitations. The strengths of this preliminary study are a homogenous population, given that the same obstetrician who supervised pregnancy delivered the baby as well. This represents an optimal doctor-patient communication situation during pregnancy. The sample size represents a limitation due to the available data and the general lack of official data on C-sections and birth process in Romania. The C-section rate in February 2014 in the unit was $64 \%$, but only $44 \%$ of the 117 women 
interviewed underwent a C-section; as a result, women who had a C-section are underrepresented in the sample. For these reasons, our findings cannot be generalized to all women giving birth in Romania. Nevertheless, we offer first-time insight into Romanian women's preferences for their mode of delivery and sketch a profile of both patients and doctors involved in the process. Thus, C-section rates across countries should be similar and based on patients' medical situations, and not on subjective approaches.

\section{Conclusion}

Our work aims at raising awareness about the high rate of $\mathrm{C}$-sections in Romania by outlining the profile of patients and doctor's behind the choice of C-section as a mode of delivery. We show that despite the preference of vaginal birth before the onset of labor, the difference between the preferred versus actual birth method may be explained by patients' perception on C-section as a better and faster procedure, with a lower degree of pain and safer for the fetus. Moreover, Romanian health system particularities regarding birth have consolidated a higher weight of patients' voice in the decision regarding the mode of delivery, beyond and despite medical indications.

We demonstrate the need for an in-depth analysis of good medical practice at hospital and country-level in Romania, possibly in the form of an thorough audit on maternal care. Improving patients' confidence in the health care system, built on competence and fitted hierarchical team position, may lead to choosing the optimal way of birth for childbirth safety and pain control.

Not the less, questions remaining to be addressed as further research directions. Among them, the critical ones refer to the reliability and accuracy of information sources that pregnant women use before deciding on their mode of delivery, the link between sexual education and the choice of delivery mode, and the desired communication patterns between doctors and patients during pregnancy. One important further research direction should address doctors' motivations towards performing more C-sections than medically needed and the proper public policy measures to encourage safe natural births.

\section{Declarations}

Ethics approval and consent to participate. Data for this study was collected in 2014, within a research grant 20062, approved by the Carol Davila University of Medicine and Pharmacy, Bucharest-Romania and maternity management. Participation in the study was voluntary.

Consent for publication : All authors have consented to the content of the paper and its publication.

Availability of data and materials: Datasets used for analysis in the current study are available from the corresponding author on request.

Competing interests: The authors declare no competing interests.

Funding: This research received no external funding. 
Authors' contributions. Conceptualization: A.A. Simionescu, A. Horobet, L. Belascu; Data curation and formal analysis: A.A. Simionescu, A. Horobet, E. Marin, L. Belascu; Investigation: A.A. Simionescu, A. Horobet, E. Marin; Methodology: A. Horobet, E. Marin; Supervision: A.A. Simionescu; Validation: L. Belascu; Writing: A.A. Simionescu, A. Horobet, E. Marin, L. Belascu. All authors have read and agreed to the published version of the manuscript.

Acknowledgments: We would like to express our deepest appreciation for the time and invaluable comments and suggestions received from professor Ana Pilar Betrán, leading WHO expert on caesarean sections, regarding our manuscript. The current version reflects the engaging insight that professor Betrán offered to us.

Consent for publication. Not applicable.

\section{References}

1. Boerma T, Ronsmans C, Melesse DY, et al. Global epidemiology of use and disparities in caesarean sections. Lancet. 2018;392(10155):1341-1348. . doi:10.1016/S0140-6736(18)31928-7.

2. Betrán AP, Ye J, Moller A-B, et al. The Increasing Trend in Caesarean Section Rates: Global, Regional and National Estimates: 1990-2014. Plos One. 2016b;11(2). :e0148343.doi:10.1371/journal.pone.0148343.

3. Visser GHA, Ayres-de-Campos D, Barnea ER, et al. FIGO position paper: how to stop the caesarean section epidemic. Lancet. 2018;392(10155):1286-1287. doi:10.1016/S0140-6736(18)32113-5.

4. STATISTA : https://www.statista.com/topics/5217/cesarean-sections/ accessed on October 2020

5. STATISTA: https://www.statista.com/statistics/807132/infant-mortality-in-romania/ accesses on October 2020.

6. https://www.macrotrends.net/countries/ROU/romania/infant-mortality-rate accessed on October 2020

7. Betrán AP, Torloni MR, Zhang JJ, Gülmezoglu AM; WHO Working Group on Caesarean Section. WHO Statement on Caesarean Section Rates. BJOG.A commentary. 2016;123(5):667-670. doi:10.1111/1471-0528.13526.

8. Opiyo N, Kingdon C, Oladapo OT, et al. Non-clinical interventions to reduce unnecessary caesarean sections: WHO recommendations. Bull World Health Organ.2020;.98(1):66-68. doi:10.2471/BLT.19.236729.

9. Mazzoni A, Althabe F, Liu NH, ,et al. Women's preference for caesarean section: a systematic review and meta-analysis of observational studies. BJOG. 2011;118(4):391-399. doi:10.1111/j.14710528.2010.02793.x.

10. Kingdon C, Baker L, Lavender T. Systematic review of nulliparous women's views of planned cesarean birth: the missing component in the debate about a term cephalic trial. Birth. 2006 
Sep;33(3):229-37. doi: 10.1111/j.1523-536X.2006.00108.x.

11. McCourt $\mathrm{C}$, Weaver $\mathrm{J}$, Statham $\mathrm{H}$,et al. Elective cesarean section and decision making: a critical review of the literature. Birth. 2007 Mar;34(1):65-79. doi: 10.1111/j.1523-536X.2006.00147.x.

12. Loke AY, Davies L, Mak YW. Is it the decision of women to choose a cesarean section as the mode of birth? A review of literature on the views of stakeholders. BMC Pregnancy Childbirth. 2019;19(1):286. Published 2019 Aug 9. doi:10.1186/s12884-019-2440-2

13. Karlström A, Nystedt A, Hildingsson I. A comparative study of the experience of childbirth between women who preferred and had a caesarean section and women who preferred and had a vaginal birth. Sex Reprod Healthc. 2011;2(3):93-99. doi:10.1016/j.srhc.2011.03.002.

14. National Institute of Statistics. Tempo database. https://insse. www.insse.ro accessed on Mai 2020

15. National Institute of Statistics. Social trends, 2019, https://insse.ro/cms/sites/default/files/field/publicatii/social_trends_in_2020_0.pdf. Accessed on June , 2020

16. Ro Health Review. Botnariu: România este pe primul loc în Europa în privința proporției nașterilor prin cezariană din totalul nașterilor din țară, 27.11.2019, https://rohealthreview.ro/botnariu-romania-estepe-primul-loc-in-europa-in-privinta-proportiei-nasterilor-prin-cezariana-din-totalul-nasterilor-din-tara/. Accessed on June 10, 2020.

17. Montilla P, Merzagora F, Scolaro E, et al. Lessons from a multidisciplinary partnership involving women parliamentarians to address the overuse of caesarean section in Italy. BMJ Global Health. 2020;5(2). doi:10.1136/bmjgh-2019-002025 .

18. Eide KT, Morken NH, Bærøe K. Maternal reasons for requesting planned cesarean section in Norway: a qualitative study. BMC Pregnancy Childbirth. 2019;19(1):102. Published 2019 Mar 29. doi:10.1186/s12884-019-2250-6

\section{Tables}

Due to technological limitations, the tables are provided in the supplementary files section.

\section{Figures}




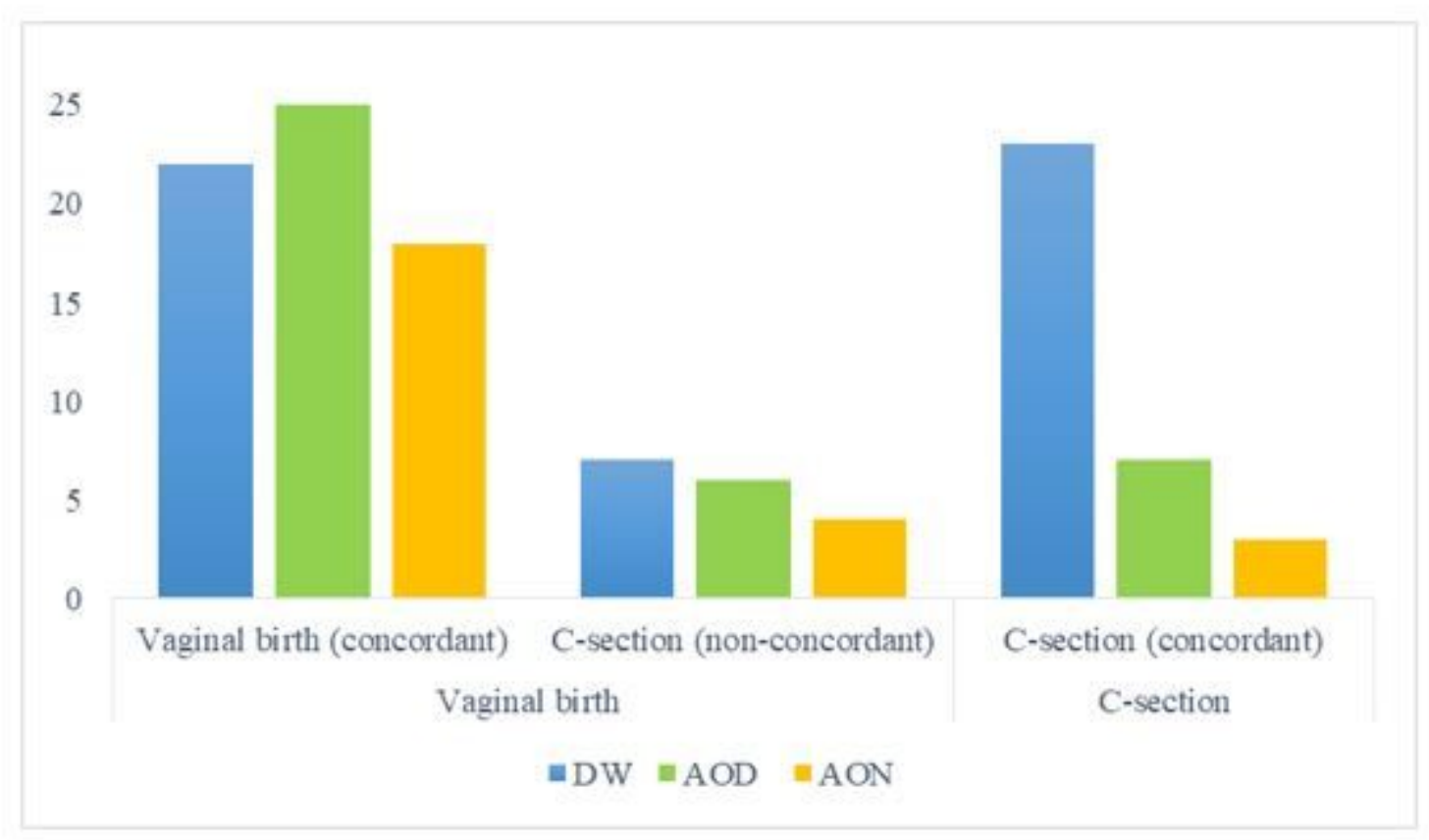

The concordant births (the same mode of delivery preferred by the patient and performed) took place mostly $A O D$, for vaginal births (25), but $D W$ for $C$-sections (23). Note: $D W$-during working hours; $A O N$-after working hours but daytime (3-10 pm); $\mathrm{AON}$ - after working hours during night time (10 pm - $8 \mathrm{am})$

\section{Figure 1}

Sample structure based on preferred versus actual mode of delivery. Legend: Out of the 117 respondents, $70.1 \%$ (82) preferred vaginal birth and $28.2 \%$ (33) preferred C-section. $79.3 \%$ (65) of women that preferred vaginal birth had vaginal birth, and $20.7 \%$ (17) delivered by C-section. None of the women who choose Csection had undergone vaginal birth. 


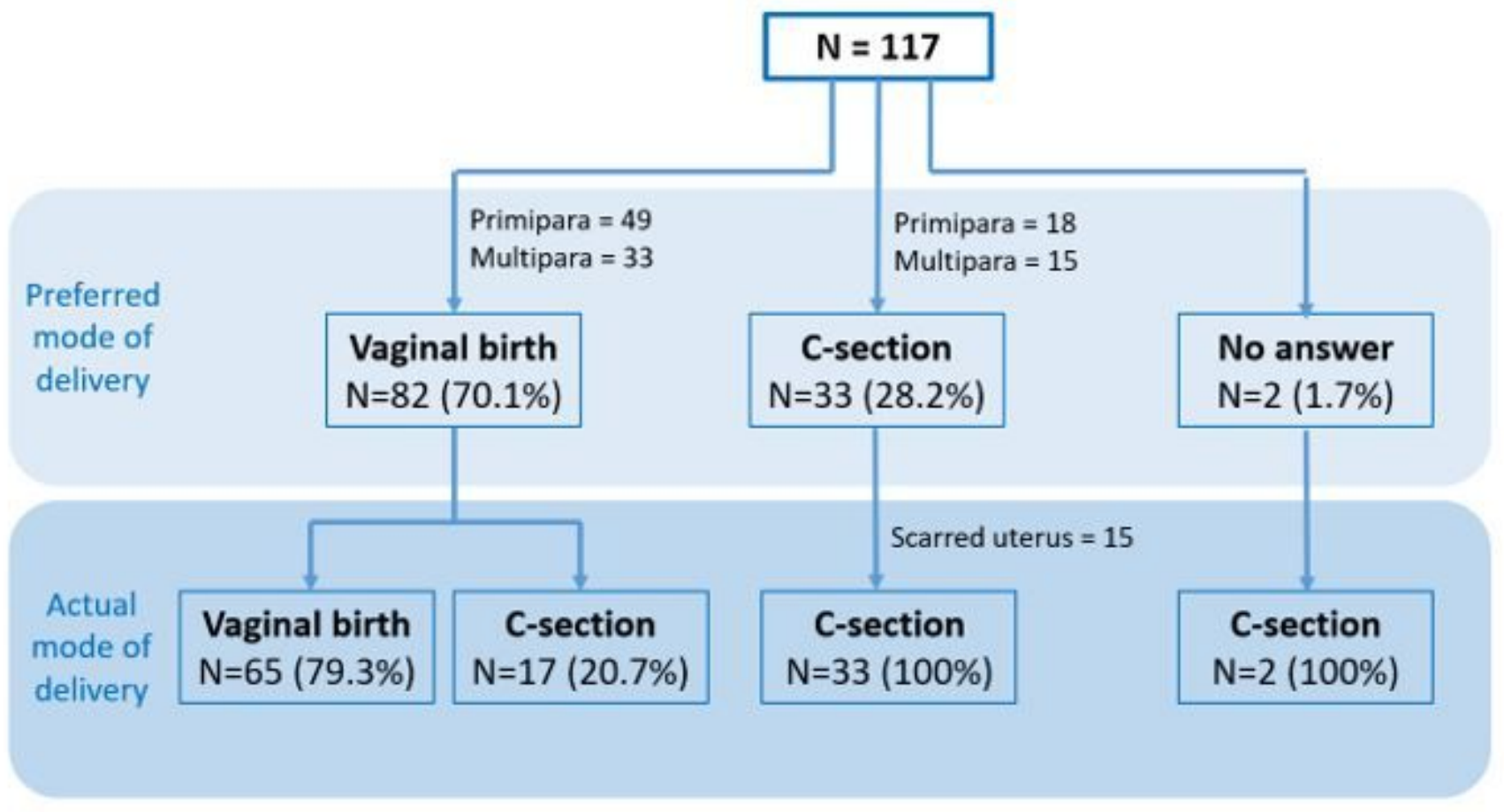

Out of the 117 respondents, $70.1 \%$ (82) preferred vaginal birth and $28.2 \%$ (33) preferred C-section. $79.3 \%$ (65) of women that preferred vaginal birth had vaginal birth, and $20.7 \%$ (17) delivered by C-section. None of the women who choose $C$-section had undergone vaginal birth.

\section{Figure 2}

Preferred versus actual mode of delivery and birth times. Legend: The concordant births (the same mode of delivery preferred by the patient and performed) took place mostly AOD, for vaginal births (25), but DW for C-sections (23). Note: DW - during working hours; AON - after working hours but daytime (3-10 pm); AON - after working hours during night time (10 pm - 8 am)

\section{Supplementary Files}

This is a list of supplementary files associated with this preprint. Click to download.

- Table1.jpg

- Table2.jpg

- Table3.jpg

- Table4.jpg

- Table5.jpg

- BMCPregnancyandChildbirthadditionalfile.docx 